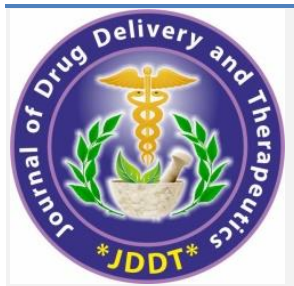

Open Access Full Text Article
Available online on 15.08.2021 at http://jddtonline.info

\section{Journal of Drug Delivery and Therapeutics}

Open Access to Pharmaceutical and Medical Research

Copyright (C) 2021 The Author(s): This is an open-access article distributed under the terms of the CC BY-NC 4.0 which permits unrestricted use, distribution, and reproduction in any medium for non-commercial use provided the original author and source are credited



Research Article

\title{
The Role of Regenerative Medicine in Wound Healing in Cases of Vesicovaginal Fistulae
}

\author{
(D)Eighty Mardiyan Kurniawati*1, (D) Nur Anisah Rahmawati 2 \\ 1 Division of Urogynecology Reconstructive, Department of Obstetrics and Gynecology, Faculty of Medicine, Universitas Airlangga, Surabaya, \\ Indonesia \\ 2 School of Midwifery, Universitas Airlangga, Surabaya, Indonesia
}

\section{Article Info:}

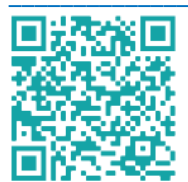

\section{Article History:}

Received 06 June 2021

Reviewed 11 July 2021

Accepted 19 July 2021

Published 15 August 2021

\section{Cite this article as:}

Kurniawati EM, Rahmawati NA, The Role of Regenerative Medicine in Wound Healing in Cases of Vesicovaginal Fistulae, Journal of Drug Delivery and Therapeutics. 2021; 11(4-S):5-8

DOI: http://dx.doi.org/10.22270/jddt.v11i4-S.4901

\section{*Address for Correspondence:}

Eighty Mardiyan Kurniawati, Urogynecology Reconstructive Division, Department of Obstetrics and Gynekology, Faculty of Medicine, Universitas Airlangga, Dr. Soetomo Hospital, Surabaya, Indonesia, Jalan Prof dr Moestopo 6-8, Surabaya 60286, Indonesia.

ORCID ID: https://orcid.org/0000-0002-7682-9275

\section{Abstract}

Background: Post-surgical wound healing in cases of vesicovaginal fistulae is a challenge because it is related to infection prevention and the long-term well-being of women.

Aim: The aim of this research was to critically review the application of regenerative medicine in wound healing. The next aim was to look in depth to see whether regenerative medicine strategies have a place in the future of wound healing in a clinical setting. More specifically, to see if these strategies would apply for vesico vaginal fistulae case in the field of urogynecology.

Method: A narrative literature review examines several previous research published at the last 5 years, containing keywords, namely vesicovaginal fistulae, regenerative medicine, wound healing. We used databases from Google Scholar, PubMed and Scopus Database.

Results: A vesicovaginal fistula is an abnormal communication between the bladder and the vagina. There are currently no precise guidelines for the postoperative management of patients after fistula repair. Transvaginal surgical procedures are a common solution for vesicovaginal fistulas. In wound healing, more attention is needed because of the risk of infection especially wound healing in the area of the reproductive organs. It should also be noted that stress urinary incontinence is a common complication. Several studies have initiated the trial process of regenerative medicine for using in urogynecological cases.

Conclusion: In the management of vesico vaginal fistula cases, regenerative medicine can be a solution in postoperative care but still needs further development and standardization.

Keywords: placenta, urogynecology, regenerative medicine

\section{INTRODUCTION}

Worldwide, vesico vaginal fistulas are stigmatized in many populations making their true incidence and prevalence difficult to articulate. ${ }^{1}$ Vesico vaginal fistula is a rare case in developed countries. ${ }^{2}$ Vesico vaginal fistula is one of the long-term morbidity due to poor obstetric care. Vesico vaginal fistula remains a scourge and of public health interest not only for medics and physically disabled but also for the inherent social, emotional and psychological strain and stress on the victims. ${ }^{1}$

Urogenital fistula is a fairly common condition in developing countries due mainly to delivery systems and surgical techniques. World Health Organization (WHO) defines this case as an abnormal tube that connects the vagina and bladder and/or rectum that can cause continuous leakage of urine or feces from the patient. There are several classifications of fistulas, but the most frequent occurrences of fistulas are vesicovaginal, rectovaginal and uterovaginal. Currently, the prevalence of genitourinary fistula is nearly 100,000 cases. Meanwhile, WHO shows that there are 0.13 million new cases every year. It occurs most frequently in India, although details are unknown. ${ }^{3}$

Prolonged and obstructed labor are the main causes of vesico vaginal fistulae. However, this is a rare occurrence in developed countries, largely due to the availability of advanced maternal health care. Factors influencing this rate include young maternal age (the physical immaturity of the mother's body causes cephalopelvic disproportion), lack of modern health facilities and skills and 'traditional' practices such as female circumcision. Vesico vaginal fistulae remain a condition with devastating physical and social consequences for the patient, regardless of the etiopathology. The successful management poses a significant challenge. Quick and accurate diagnosis is essential. Timely repair by an experienced fistula surgeon, following the basic principles of careful surgery, will improve outcomes and limit the clinical distress and suffering that vesico vaginal fistulae invariably causes (Garthwaite, 2010). This disease is a medically and psychosocially devastating condition for the patient. Diagnosis is easy but complicated in treatment decisions. The best results were observed with the transvesical- 
transvaginal approach. ${ }^{5}$ Surgery is one solution in cases of vesico vaginal viscera.

In postoperative case management, normal wound healing is a dynamic and complex dual-phase process involving coordinated interactions between growth factors, cytokines, chemokines, and various cells. Failure in this phase can cause the wound to become chronic and have abnormal scar tissue formation. Chronic wounds affect the patient's quality of life, because they require repeated treatment and incur large medical costs. ${ }^{6}$ The global burden of disease-related injuries is an increasingly significant public health problem. Current treatments are often expensive, time consuming and limited in their efficacy in chronic wounds. The challenge of overcoming current barriers related to wound care requires innovative management techniques. Regenerative medicine is a new field of research that focuses on repairing, replacing or regenerating cells, tissues or organs to restore impaired function. Regenerative medicine has the potential to support the design of specific targeted therapies in acute and chronic wound healing. This personalized approach can ultimately reduce the burden of disease associated with wound healing. More evidence is needed in the form of large animal studies and clinical trials to assess the long-term efficacy and safety of this new treatment.7

The aim of this research was to critically review the application of regenerative medicine in - wound healing the field of urogynecology. The next aim was to look in depth to see whether regenerative medicine strategies have a place in the future of wound healing in a clinical setting. More specifically, to see if these strategies would apply for vesico vaginal fistulae case.

\section{METHOD}

A narrative literature review research examines several previous published research to identify and summarize, avoid duplication of research, and look for new fields of study that have not been studied. The published article included in the literature at the last 5 years, containing keywords, namely vesicovaginal fistulae, regenerative medicine, wound healing. We used databases from Google Scholar, PubMed and Scopus Database. We review antenatal policies during the pandemic, the physical and psychological impacts that occur and then review them in the discussion.

\section{RESULTS AND DISCUSSION}

\section{Vesicovaginal fistulae treatment}

A vesicovaginal fistula is an abnormal communication between the bladder and the vagina. Because clinical scenarios vary, it is difficult to frame uniform guidelines for the management of vesicovaginal fistulas. Most conservative methods have a reported success rate of between $3 \%$ and $100 \%$. This series has included a small number of patients without long-term follow-up. Therefore, the choice of a conservative method depends on the preference of the physician with a thorough explanation that surgical intervention will be required if conservative treatment fails. Conservative methods should be used in carefully selected patients. The decision to repair a vesico-vaginal fistula surgically should be taken early and should be based on sound clinical judgment after considering all factors concerning the fistula. The transvaginal route is preferred, because it has low morbidity, higher success rates, and minimal complications. When facilities are available, all patients can be referred to a tertiary care center where stateof-the-art expertise and resources are available. This may not be true for many developing countries where the economy and health care systems are suboptimal. ${ }^{8}$ The vaginal approach is preferred over the abdominal approach for repair of all vaginally accessible vesico-vaginal fistulas, whether of obstetric or gynecological origin. ${ }^{9}$

\section{Post-surgery wound healing mechanism}

There are currently no precise guidelines for the postoperative management of patients after fistula repair. It should also be noted that stress urinary incontinence is a common complication after repair of a vesico vaginal fistula. ${ }^{10}$ Several host and surgical factors have been identified to increase the risk of sequelae of infection after pelvic surgery. Many of these risk factors are modifiable and care must be taken to address them to reduce the chance of infection. It should be noted that postoperative cuff and hip abscess are one of the most common complications of gynecological surgery. Evaluation of preoperative and postoperative risk factors and managing modifiable risk factors can reduce infection rates. ${ }^{11}$ Specific wound closure techniques improve wound healing after gynecological surgery. ${ }^{12}$ The surgeon's ability to dissect, detect and correct the defect causing the prolapse will affect the surgical outcome. These ingredients can be used as adjuvants for primary tissue healing to improve results. ${ }^{13}$

In some cases, treatment of the reproductive organ, requires careful care. As with perineal and vaginal wounds, the management of perineal wounds can be very frustrating because they are always contaminated from the anogenital tract. In addition, the apparent skin defect may be associated with significant three-dimensional dead space in the pelvic region. These wounds tend to become chronic and stubborn if proper wound management is not performed at the right time. These wounds usually occur after tumor excision, urogynecological procedures after trauma or as a result of infectious pathologies such as hideradenitis suppurativa or after thermal burns. ${ }^{14}$ Complications of perineal wound are a long-term problem for patients with abdominoperineal resection (APR). Complication rates as high as $60 \%$ have been reported, with the most common complication being delayed perineal wound healing. Hypoalbuminemia is an independent risk factor for delayed wound healing, which consequently leads to prolonged hospitalization. ${ }^{15}$ Some cases of injuries to the perineum often lead to cases of restitching. Some women show complete perineal wound dehiscence which ultimately chooses secondary suturing. Patients need to be explained about their wound care procedures. ${ }^{16}$

Wound healing processes such as post-surgical procedures on vesico vaginal fistulas need to be considered. Accelerating the wound healing process will increase the possibility of faster healing and prevent post-surgical infections. Improved recovery after surgery protocol was developed to speed up postoperative recovery. Improved recovery after surgery in the urogynecological population results in a greater proportion of same-day discharges and higher patient satisfaction. ${ }^{17}$ Some urogynecological cases are women with old age. This affects the mechanism of wound healing and slower regeneration when compared to young women. Vaginal wound healing is a major determinant of surgical outcome after pelvic reconstructive surgery. Since most of these surgeries are performed on peri and postmenopausal women, it is important to understand how estrogen deficiency affects this process. ${ }^{18}$

\section{Regenerative medicine and wound healing}

Efforts to improve wound healing after vesico vaginal fistulae surgery have come to light. Regenerative medicine is believed to be an important part of postoperative patient care. Wound healing is a logical target for regenerative 
medicine due to the accessibility and structure of the skin, regenerative healing properties, lack of good limb salvage treatments, and current use of cell therapy. However, broader knowledge of pathophysiological targets is needed to inform regenerative strategies, and new technologies must demonstrate value in terms of outcomes and associated health economic measures to achieve successful market access and penetration. Wound healing is a logical target for the early development of regenerative strategies due to its regenerative wound healing properties, accessibility and skin structure, lack of good limb salvage treatments, and early adoption of cell therapy in the field. Regenerative medicine strategies developed in other fields of medicine may also be useful for wound healing given the similarities in signaling pathways and cell development. ${ }^{19}$ The lack of standardization makes it much more difficult to compare the data collected and the different types of treatment. Despite some promising results from research and early-phase clinical studies, wound care and skin regeneration are still considered an unmet clinical need. ${ }^{20}$

In the management of vesicovaginal fistulae cases, the problem of fistuloplasty complications of vesicovaginal fistulas remains highly relevant both for modern surgeons and for patients. Optimization of morphological characteristics with local interstitial application of PlateletRich Plasma (PRP) can positively influence the outcome of surgical treatment of vesico vaginal fistulae. Taking into account the statistically significant reduction in the activity of the inflammatory process, the complete healing of erosive and ulcerative lesions, and the decrease in the thickness of the fibrosis in the stromal layer of the fistula tissue, the application of PRP therapy in the surgical treatment of vesico vaginal fistulae should be considered appropriate and justifiable. ${ }^{21} \mathrm{~A}$ vesico-vaginal fistula is an abnormal opening between the bladder and vagina, which is a stigmatized disease in many developing countries. Leakage of urine into internal organs can cause serious complications and delay wound repair. Conventional vesico vaginal fistulae treatment requires skilled suturing to provide a tension-free and watertight closure. Additionally, there are no clinically approved surgical glues that work in wet and highly dynamic environments such as the urinary system. In this work, for the potential for closure and regeneration of clinical vaginal vesico fistulas, a study developed an immiscible shellfish protein-based bioglue with fast, strong, wet adhesion and adjustable rheological properties. This immiscible regenerative bioglue can be successfully used for sealing fistulas and a wide variety of further surgical applications as an adjuvant to conventional suture methods. ${ }^{22}$

Much effort has been focused on developing new therapeutic approaches to wound care. Stem cell-based therapeutic strategies have been proposed to treat these wounds. They have shown considerable potential to increase the rate and quality of wound healing and skin regeneration. However, there are many challenges to using stem cells in skin regeneration. In this review, we present several published datasets on the use of embryonic stem cells, induced pluripotent stem cells, and adult stem cells in wound healing. In addition, we will discuss the different angles in which these cells can contribute to their unique features and point out their current weaknesses. Wound healing has always been the most challenging problem due to the presence of various cells and molecules that work in an orderly manner. Any disturbance can lead to failure of healing and result in the progression of an acute wound to a chronic wound. So far, various procedures have been used in the treatment of skin ulcers among which cell-based therapies especially adult stem cells have emerged as promising treatments for promoting scarless wound healing. Through the ability of mesenchymal stem cells in immunomodulation and tissue regeneration, they have received special attention from other adult stem cells. Clinical data show that autologous MSC transplantation promotes healing in all phases of wound repair. However, harvesting and isolating a high-purity optimized collection of MSCs hinders the progress of developing new therapies. Thus, the characterization of MSCs with niche-specific factors is still a challenge for researchers. To overcome these limitations, an understanding of the cellular and molecular mechanisms underlying stem cell action is required. Furthermore, methods of improving stem cell delivery and identification of ideal sources are required for the clinical application of these cells in wound healing. ${ }^{6}$

Cystoscopy-guided stem cell injection could be a possible treatment of vaginal vesico fistulas in an outpatient setting with minimal patient discomfort, but should be further optimized according to, for example, support gel formation, cell survival, and cell detection methods. ${ }^{23}$ Postoperative management is very important. High fluid intake and output must be maintained until urine is clear of blood; Continuous bladder drainage is essential. If the catheter is blocked, this is most likely the cause of repair failure and the nurse should be instructed to ensure that the catheter flows freely, both day and night. The bladder should remain catheterized for 23 weeks after repair. Cystography is performed prior to catheter removal if there is any doubt about the integrity of the repair. Anticholinergic drugs should be given if bladder spasms occur. As far as causing discomfort to the patient, it has been suggested that these contractions may interfere with repair healing. An antiseptic tampon is placed in the vagina for a day. The patient should avoid sexual intercourse for 3 months. Regardless of the surgical approach to vaginal vesico fistulas, the key to postoperative management is maintenance of a dry, uninfected suture line. For this reason, the use of antibiotics is recommended for a long time after surgery, usually until all catheters are removed. ${ }^{24}$

\section{CONCLUSION}

In the management of vesico vaginal fistula cases, regenerative medicine can be a solution in postoperative care but still needs further development and standardization. The recommendation for further research is that it is necessary to conduct research on the development of regenerative medicine or stem cells that can be developed for patients in urogynecology.

\section{REFERENCES}

1. Umeora OUJ, Emma-Echiegu NB. Vesico-Vaginal Fistula in Developing Countries - Time to Turn off The Tap. J Preg Child Health, 2015; 2:e120

2. Ahmed S. El-Azab, Hassan A. Abolella, Mahmoud Farouk. Update on vesicovaginal fistula: A systematic review, Arab Journal of Urology, 2019; 17(1):61-68, https://doi.org/10.1080/2090598X.2019.1590033

3. Rodjani, A., Sandy, N.J. Prevalence of urogynecology fistula in Cipto Mangunkusumo National Hospital from 2011-2017. IJBS, 2021; 15(1): 48-50

4. Garthwaite M, Harris N. Vesicovaginal fistulae. Indian J Urol, 2010; 26(2):253-256 https://doi.org/10.4103/0970-1591.65400

5. Taher, T. R., Zulfikar, Wahyudi, I., \& Rodjani, A. Vesico-Vaginal Fistula: Experience of 11 Years. Indonesian Journal of Urology, 2013 https://doi.org/10.32421/juri.v20i1.39

6. Nourian Dehkordi, A., Mirahmadi Babaheydari, F., Chehelgerdi, M. et al. Skin tissue engineering: wound healing based on stem-cell- 
based therapeutic strategies. Stem Cell Res Ther, 2019; 10(111) https://doi.org/10.1186/s13287-019-1212-2

7. Calver pang, Amel Ibrahim, Neil Bulstrode, Patrizia Ferretti. An overview of the therapeutic potential of regenerative medicine in cutaneous wound healing: Advances and limitations in regenerative medicine for stimulating wound repair. International Wound Journal, 2017; 14(3) https://doi.org/10.1111/iwj.12735

8. Rajaian S, Pragatheeswarane M, Panda A. Vesicovaginal fistula: Review and recent trends. Indian J Urol, 2019; 35(4):250-258 https://doi.org/10.4103/iju.IJU_147_19

9. Kumar M, Agarwal S, Goel A, Sharma A, Agarwal A, Pandey S, Sankhwar S, N: Transvaginal Repair of Vesico Vaginal Fistula: A 10-Year Experience with Analysis of Factors Affecting Outcomes. Urol Int, 2019; 103:218-222 https://doi.org/10.1159/000499411

10. Christopher J. Hillary, Christoper R. Review The choice of surgical approach in thetreatment of vesico-vaginal fistulae. Chapple Asian Journal of Urology, 2018; 5:155e159 https://doi.org/10.1016/j.ajur.2018.01.002

11. Mark P. Lachiewicz, Laura J. Moulton, Oluwatosin Jaiyeoba, "Pelvic Surgical Site Infections in Gynecologic Surgery", Infectious Diseases in Obstetrics and Gynecology, 2015; 614950: 8 https://doi.org/10.1155/2015/614950

12. Cedric Emanuel Boesch, Wolfgang Umek. Effects of Wound Closure on Wound Healing in Gynecologic Surgery A Systematic Literature Review. The Journal of reproductive medicine, 2009; 54(3):139-44

13. Nieuwoudt, A., Appleby, C., \& Mukhopadhyay, S. Native Tissue Repair and Principles of Wound Healing: Introducing the Concept of Regenerative Surgery in Vaginal Prolapse Repair. Journal Of Clinical Gynecology And Obstetrics, 2015; 4(2):197202 https://doi.org/10.14740/jcgo336w

14. Sharma RK, Parashar A. The management of perineal wounds. Indian J Plast Surg. 2012; 45(2):352-363 https://doi.org/10.4103/0970-0358.101318

15. Chang, CC., Lan, YT., Jiang, JK. et al. Risk factors for delayed perineal wound healing and its impact on prolonged hospital stay after abdominoperineal resection. World J Surg, 2019; Onc 17:226 https://doi.org/10.1186/s12957-019-1768-4
16. Okeahialam NA, Thakar R, Kleprlikova H, Taithongchai A, Sultan AH. Early re-suturing of dehisced obstetric perineal wounds: A 13-year experience. Eur J Obstet Gynecol Reprod Biol, 2020; 254:69-73 https://doi.org/10.1016/j.ejogrb.2020.09.013

17. Carter-Brooks CM, Du AL, Ruppert KM, Romanova AL, Zyczynski HM. Implementation of a urogynecology-specific enhanced recovery after surgery (ERAS) pathway. Am J Obstet Gynecol, 2018; 219(5):495.e1-495.e10 https://doi.org/10.1016/j.ajog.2018.06.009

18. Abramov Y, Golden B, Sullivan M, Goldberg RP, Sand PK. Vaginal incisional wound healing in a rabbit menopause model: a histologic analysis. Int Urogynecol J. 2012; 23(12):1763-9 https://doi.org/10.1007/s00192-012-1793-0

19. Gurtner GC, Chapman MA. Regenerative Medicine: Charting a New Course in Wound Healing. Adv Wound Care (New Rochelle), 2016; 5(7):314-328.

https://doi.org/10.1089/wound.2015.0663

20. Nilforoushzadeh MA, Sisakht MM, Seifalian AM, Amirkhani MA, Banafshe HR, Verdi J, Sharifzad F, Taghiabadi E. Regenerative Medicine Applications in Wound Care. Curr Stem Cell Res Ther, 2017; 12(8):658-674 https://doi.org/10.2174/1574888X12666170929123842

21. Medvedev VL, Opolskiy AM, Gorban NA, Kogan MI. [Morphological analysis of the structure of parafistulous tissues in patients with vesicovaginal fistulas by the local interstitial application of platelet-rich plasma]. Urologiia, 2021 Mar; 1:2126 https://doi.org/10.18565/urology.2021.1.21-26

22. Kim HJ, Pyun JH, Park TY, Yoon SG, Maeng SW, Choi HS, Joo KI, Kang SH, Cha HJ. Preclinical evaluation of a regenerative immiscible bioglue for vesico-vaginal fistula. Acta Biomater. 2021; 15(125):183-196 https://doi.org/10.1016/j.actbio.2021.02.037

23. Jepsen MS, Sellathurai J, Conti A, Schrøder HD, Lund L. Treatment of Vesicovaginal Fistulas With Autologous Cell Injections-A Randomized Study in an Animal Model. Technol Cancer Res Treat. 2017; 16(6):793-800 https://doi.org/10.1177/1533034617691615

24. Stamatakos M, Sargedi C, Stasinou T, Kontzoglou K. Vesicovaginal fistula: diagnosis and management. Indian J Surg. 2014; 76(2):131-136 https://doi.org/10.1007/s12262-012-0787-y 